\title{
Editor's Message: Two new editors for Hydrogeology Journal
}

\section{Clifford Voss}

Keywords Editorial · Hydrogeology Journal

During 2015, HJ editors Jimmy Jiao and Vincent Post ended their terms after several years of dedicated and excellent work to support the journal and authors of journal articles. At the same time, Martin Appold and Jean-Michel Lemieux began as our new editors. Jimmy served as an HJ editor for seven years (since 2008) and Vincent served as HJ editor for five years (since 2010). Jimmy and Vincent began to pass their work to Martin and Jean-Michel in early 2015, and in July 2015, Martin and Jean-Michel took over fully. Jimmy has mentioned that he is planning to write a book and Vincent will use his extra time to expand his research efforts. We wish both well in their future endeavors.

Martin Appold is an associate professor in the Department of Geological Sciences at the University of Missouri (USA). He was initially drawn to geology by an interest in ore deposits, leading to a bachelor's degree in geology from Washington University (USA) in 1990 and a master's degree in economic geology from the University of Michigan (USA) in 1992. During his master's studies, Martin became interested in numerical modeling of flow and transport in porous media, and went to Johns Hopkins University (USA) to pursue a doctorate in hydrogeology, completed in 1998. Martin continued to do research in hydrogeology as a post-doctoral fellow at Louisiana State University and as a faculty member at the
Universities of Iowa and Missouri (USA). His main interest concerns the role of groundwater and other subsurface fluids in geologic processes such as formation of hydrothermal ore deposits and hydrocarbon fields, and more recently, he has focused on geotechnical problems including $\mathrm{CO}_{2}$ sequestration. Martin told us that he also has an active interest in the effects of hydrology on his fruit and vegetable garden.

Jean-Michel Lemieux has been an associate professor in the Department of Geology and Geological Engineering at Université Laval (Canada) since 2009 and a member of Canada's Centre d'Études Nordiques (CEN, Centre for Northern Studies). He has a bachelor's degree in geological engineering (2000) and a master's degree in earth sciences (2002) from Université Laval. JeanMichel's doctoral research in earth sciences at the University of Waterloo (Canada), completed in 2007, focused on hydrologic impacts of glaciations in Canada. He also worked as a hydrogeologist at the engineering firm SNC-Lavalin in Montréal (20062007), completed a post-doctoral fellowship at the University of Liège in Belgium (2007-2008), and was a research fellow at the ETH-Zurich, Switzerland (2008-2009). He is interested in the study of past, present and future hydrogeological processes with a focus on numerical modeling. Jean-Michel is also a strong-applecider-making hobbyist, so he tells us to be certain to stop by Université Laval for a private tasting if we travel in the Belle Province!

Received: 25 June 2015 / Accepted: 26 June 2015

Published online: 7 July 2015

(C) Springer-Verlag Berlin Heidelberg (outside the USA) 2015

C. Voss is the executive editor of Hydrogeology Journal (HJ)

C. Voss (『)

US Geological Survey, 345 Middlefield Road, MS 496, Menlo Park, CA 94025, USA

e-mail: cvoss@usgs.gov 